\title{
The perception of surface roughness by active and passive touch
}

\author{
SUSAN J. LEDERMAN \\ Queen's University, Kingston, Ontario K7L 3N6, Canada
}

\begin{abstract}
Subjects made magnitude estimates of the roughness of metal gratings by both active and passive touch (with object movement). The perceived magnitude of surface roughness and the consistency of such judgments were identical under the two modes of tactual examination. The results have implications for sensory physiology studies of the cutaneous peripheral mechanisms that underlie texture. They also question the prevailing notion in somethesis and tactual perception that active touch is always superior to passive touch.
\end{abstract}

Recently, there has begun to develop an interest in the corresponding peripheral coding mechanisms for complex, spatiotemporal events produced when the hand touches textured surfaces (e.g., Darian-Smith, Davidson, \& Johnson, 1980; Darian-Smith \& Oke, 1980; LaMotte, 1977). In the single-unit work to date, the textures have been moved across the stationary hands of monkeys; however, the corresponding psychophysical work has typically involved human subjects actively examining the same textured surfaces. Previously, it was assumed that active and passive modes of stimulation yield similar judgments of texture. Katz (1925) is cited as having shown little difference in roughness discrimination by active vs. passive touch. Unfortunately, he provided no quantitative data to support his observations. Therefore, the current study experimentally evaluated the relative performance of a roughness perception task by active vs. passive touch.

According to Katz (1925; see Krueger, in press), vibration is the sine qua non for texture perception; he thus emphasized the necessity of relative motion between skin and surface. Without motion, there could be no vibration and, therefore, no perception of texture. The temporal aspects of vibration seemed most important (Krueger, in press). More recently, Taylor and Lederman (1975) offered a model of roughness perception that likewise argued that relative motion is necessary; however, unlike Katz, they suggested that vibration per se is crucial for perceiving roughness only in that it prevents the cessation of mechanoreceptor activity. The Taylor and Lederman model favors an interpretation of roughness perception based on the intensive/spatial aspects of skin deformation.

The author's address is S. J. Lederman, Department of Psychology, Queen's University, Kingston, Ontario K7L 3N6, Canada. This research was supported by Natural Sciences and Engineering Research Council of Canada Grant A9854. Thanks are extended to R. Harris and L. Baxter for conducting the research and to J. Loomis and D. Williams for helpful comments on previous drafts of the manuscript.
Regarding the outcome of the current experiment, therefore, the Taylor and Lederman (1975) model and, likely, Katz's (1925) work would predict that magnitude estimates of roughness should be identical, whether active or passive touch is used (provided that force remains constant). The relative consistency of the judgments by active and passive touch is also considered, although neither interpretation makes a specific prediction regarding the outcome.

\section{METHOD}

Subjects

Eight young adults, all right-handed for writing, participated.

\section{Stimuli and Apparatus}

A set of eight aluminum plates $(14.0 \times 11.4 \times .5 \mathrm{~cm})$ was used; linear gratings were machined into the middle third section of the surfaces. The width of the ridges was constant at $.250 \mathrm{~mm}$; the spacing between the ridges ("groove width") varied from .175 to $1 \mathrm{~mm}$ (in increments of $.125 \mathrm{~mm}$ from .250 to $1 \mathrm{~mm}$ ). Groove depth and groove width were identical for each plate.

A balance apparatus (Lederman \& Taylor, 1972) was used to control the force applied. Plates were inserted one at a time into a stimulus tray at one end of the balance arm; counterweights could be added or subtracted at the other end. The subject applied sufficient force in both active and passive conditions to maintain the balance-arm level during the touching process. Three force conditions were used: 28,112 , and $224 \mathrm{~g}$. For the passive touch condition, a variable-speed motor was used to drive an eccentric cam. Rotary motion of the cam was converted into linear motion of the balance arm via a metal rod that connected the two. Extraneous vibrations were damped by means of a rubber connection between the horizontal metal rod joined to the cam and another rod mounted vertically on the movable balance arm. A metal finger support was mounted over the stimulus end of the balance arm. Subjects slipped the middle three fingers of their right hand down through the prongs of the support to touch the stimulus surface below; however, only the middle finger was actually used to examine the surface. An audio generator and relay timer were used to produce brief $400-\mathrm{Hz}$ tones in headphones during "active touch" trials. The auditory signals cued the subject as to the correct hand speed.

\section{Experimental Design}

A repeated-measures, completely crossed design was used in which each subject estimated the roughness of eight surfaces with three different forces and two modes of touch (active, 
passive). The experiment was repeated in seven sessions, one session per day; an additional three sessions were included at the beginning of the study. Order of presentation of plates, forces, and modes was determined according to a controlled randomization procedure; the one stipulation was that the narrowest and widest groove widths were never presented consecutively.

\section{Experimental Procedure}

Training session. On the 1st day, subjects were trained to use the balance apparatus in both the active and passive modes of examination. In the active condition, subjects were trained to move their middle finger back and forth a given distance, using the tones as an indication that direction of finger movement should be changing coincidentally with the cue. The interval between tones was arranged so that movement of the hand across the central grating would occur at the rate of $4.8 \mathrm{~cm} / \mathrm{sec}$. Subjects were instructed to move their fingers at a constant speed across the grating in both directions. It was explained that the relative speed of movement between hand and object was intended to be identical in the active and passive conditions.

In the passive trials, the balance arm was magnetically centered at the close of each trial; however, it seemed best to begin all touching from the "neutral" smooth sides of the plates. Thus, subjects were taught to keep the balance arm away from their fingertips by pushing down on it with the butt of their right hand. In this way, when the balance arm began moving from the center position, no contact between finger and plate occurred. When the balance arm arrived at the point of maximum displacement on the subjects' left, they allowed the balance arm to gently rise until finger and plate made contact without bouncing. A maximum of four complete passes across the plate was permitted in both active and passive modes. The speed of the balance arm moving under the subjects' stationary finger was set at $4.8 \mathrm{~cm} / \mathrm{sec}$ to match the active movement condition. Subjects wore headphones throughout the entire session, although the tones were only present during the active trials.

Practice and test sessions. At the beginning of each practice and experimental day, subjects were presented sample plates described as "one of the roughest and one of the smoothest." Sample plates consisted of the $.175-\mathrm{mm}$ and $1-\mathrm{mm}$ groove widths presented at $28 \mathrm{~g}$ and $224 \mathrm{~g}$, respectively. They were examined once in the active mode and once in the passive mode. Presentation order of the plates and modes was random.

A modified magnitude-estimation procedure was used. Subjects were instructed to assign any positive nonzero number in proportion to the apparent roughness of the plates. Subjects were told that they should be prepared to let their number systems extend beyond the range of the sample plates if they felt this was appropriate. Subjects were told to maintain their number systems across the entire session.

\section{RESULTS}

The magnitude-estimate scores were logarithmically transformed to yield normally distributed data. An analysis of variance (repeated-measures design) was performed, the factors being day, mode, force, and groove width. As in previous experiments (e.g., Lederman, 1974), main effects of groove width and force were highly significant $[F(7,40)=59.7, p<.001$, and $F(2,14)$ $=21.6, \mathrm{p}<.001$, respectively]: Apparent roughness increased with both increasing groove width and increasing finger force. The interaction term, Groove Width by Force, was also highly significant $[F(14,98)=4.2$, $\mathrm{p}<.001]$, indicating that the force effect tended to increase as groove width increased. These effects are shown in Figure 1: The geometric means of the magni-

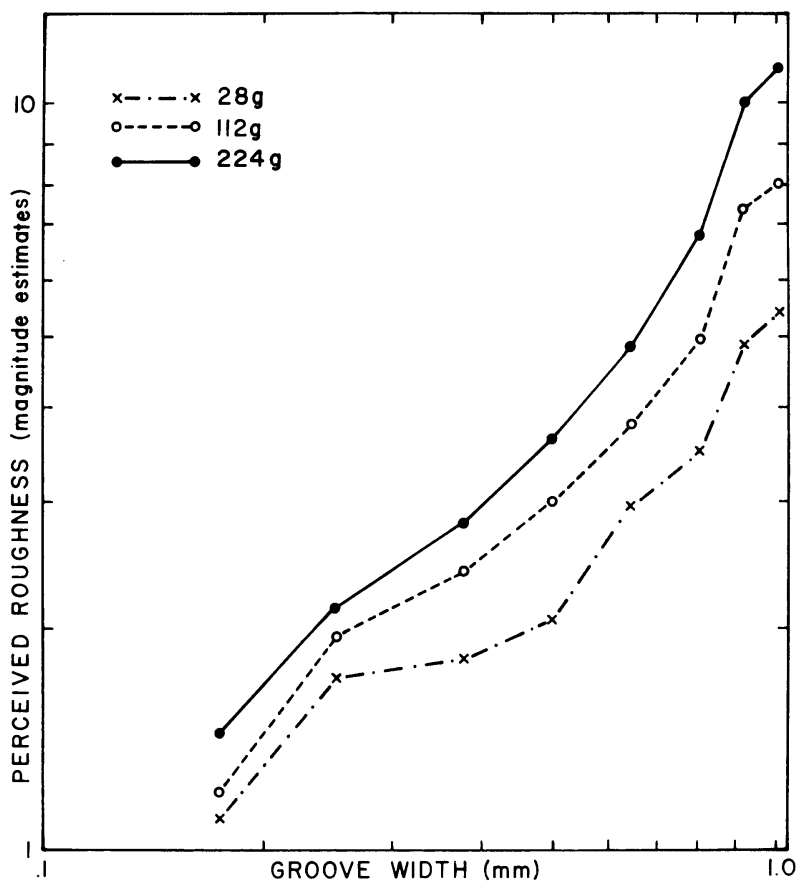

Figure 1. The perception of surface roughness (magnitude estimates of roughness) as a function of groove width and finger force. The data for the active and passive touch conditions have been combined, since there was no statistical difference between the two conditions. Geometric means are shown.

tude estimates of roughness are plotted as a function of groove width using log scales. The data for the active and passive touch conditions have been combined because none of the effects involving the "mode" factor was statistically significant (nor were any of the remaining main effects or interactions). There was thus no difference in the magnitude estimates of perceived roughness, whether the person moved his or her hand across a stationary surface or the surface was moved across the stationary hand. In fact, none of the effects involving mode accounted for more than $.1 \%$ of the variance (cf. 25\% of the variance for the effect of groove width).

A second analysis of variance was performed on the transformed data using an estimate of the variance across days. This analysis, called ANOVAVA (see Appendix to Lederman \& Taylor, 1972) assessed the relative consistency of estimates made in the active and passive conditions. An additional logarithmic transformation was required to render the badly skewed variance distribution normal. The results indicate that variability tended to decrease significantly with both increasing groove width and force $[\mathrm{F}(7,49)=4.5$, $\mathrm{p}<.001$, and $\mathrm{F}(2,14)=13.9, \mathrm{p}<.001$, respectively] The interaction term, Groove Width by Force, was also statistically significant $[F(14,98)=1.98, p<.05]$. However, of greater interest in the present experiment is the fact that active and passive judgments were not significantly different $[F(1,7)=5.10, p>.05]$. No other effects involving mode were statistically signifi- 
cant, either. Once again, it should be noted that the percent of the variance accounted for by groove width was almost 300 times that accounted for by any factor involving mode.

\section{DISCUSSION}

The results of the current experiment are relevant to the study of cutaneous peripheral coding mechanisms of texture. They indicate that it is reasonable to correlate the single-unit recordings obtained in response to passive stimulation of the skin with the psychophysical data on roughness typically obtained by active touch, provided the force applied is the same in both conditions. As shown in earlier studies (e.g., Lederman \& Taylor, 1972), both groove width and finger force strongly affect the perception of surface roughness by active touch. Increases in both of these factors result in substantial increases in felt roughness; the results of the current study show similar effects when passive touch with object movement is employed.

The finding ${ }^{1}$ that the magnitude estimates are identical, whether subjects move their hands across a stationary surface or the surface is moved across the stationary hand, confirms the prediction made by the Katz (1925) and Taylor and Lederman (1975) interpretations of roughness perception. The study also indicates that perceived roughness does not depend upon movements of the hand per se. As Katz (1925) and Taylor and Lederman (1975) have argued, relative motion is required between hand and object; however, this motion can be produced by a moving object or by the moving hand. Either way, the vibrations, which the above investigators consider necessary for the perception of roughness, are produced in the skin. Intuitively, one might have expected that the additional information provided by the observer's self-produced movements (i.e., additional kinesthetic cues and/or efferent copy) would have increased the reliability of the texture judgments. However, this was not borne out by the data.

Clearly, the current study and the earlier work of Katz (1925) also have important implications for the active/passive touch issue as it is viewed today by most investigators of somesthesis and tactual perception. These fields continue to assert the general superiority of active as opposed to passive touch (e.g., Goldstein, 1980; Gordon, 1978; Kenshalo, 1978; Stevens \& Green, 1978). Yet there is clearly no difference in the perception of roughness by active and passive touch (with object movement); nor, apparently, is there any difference in the perception of braille characters under similar conditions of tactual examination (Grunwald, 1978; Day \& Dickinson, Note 1), or in yet other situations in which certain form-related tasks are involved (e.g., Schwartz, Perey, \& Azulay, 1975). It is therefore inappropriate to continue making such general statements regarding the relative superiority of active touch without regard to the particular task.

\section{REFERENCE NOTE}

1. Day, R. H., \& Dickinson, R. G. Learning to identify braille numerals with active and passive touch. Unpublished research note, Monash University.

\section{REFERENCES}

Darian-Smith, I., Davidson, D., \& Johnson, K. Peripheral neural representation of the two spatial dimensions of a textured surface moving across the monkey's finger pad. Journal of Physiology, 1980, 309, 135-146.

Darian-Smith, I., \& OKe, L. Peripheral neural representation of the spatial frequency of a grating moving at different velocities across the monkey's finger pad. Journal of Physiology, 1980, 309, 117-133.

Goldstein, E. G. Sensation and perception. Belmont, Calif: Wadsworth, 1980.

Gordon, G. (Ed.), Active touch. The mechanism of recognition of objects by manipulation: A multidisciplinary approach. Oxford: Pergamon Press, 1978.

Grunwald, A. P. On braille and braille machines. Sensory World, $1978,3,4$.

Katz, D. Der Aufbau der Taswelt. Zeitschrfit für Psychologie, 1925, 11, 1-270.

Kenshalo, D. Biophysics and psychophysics of feeling. In E. Carterette \& M. Friedman (Eds.), Handbook of perception (Vol. VIb). New York: Academic Press, 1978.

KRUEger, L. Tactual perception in historical perspective: David Katz's World of Touch. In W. Schiff \& E. Foulke (Eds.), Sourcebook of tactual perception. New York: Cambridge University Press, in press.

LaMotTe, R. H. Psychophysical and neurophysiological studies of tactile sensibility. In $H$. Hollies \& $R$. Goldman (Eds.), Clothing comfort: Interaction of thermal, ventilation, construction, and assessment factors. Ann Arbor, Mich: Science Publishers, 1977.

LEDERMAN, S. J. Tactile roughness of grooved surfaces: The touching process and effects of macro- and microsurface structure. Perception \& Psychophysics, 1974, 16, 385-395.

Lederman, S. J., \& TAYLOR, M. M. Fingertip force, surface geometry, and the perception of roughness by active touch. Perception \& Psychophysics, 1972, 12, $401-408$.

Schwartz, A. S., Perey, A. J., \& Azulay, A. Further analysis of active and passive touch pattern discrimination. Bulletin of the Psychonomic Society, 1975, 6, 7-9.

Stevens, J. C., \& Green, B. History of research on feeling. In E. Carterette \& M. Friedman (Eds.), Handbook of perception (Vol. VIb). New York: Academic Press, 1978.

TAYlor, M. M., \& Lederman, S. J. Tactile roughness of grooved surfaces: A model and the effect of friction. Perception \& Psychophysics, 1975, 17, 23-36.

\section{NOTE}

1. The pattern of results obtained in this experiment was also replicated in a second experiment not reported here. The only experimental difference was that the heaviest force used in the second experiment was $252 \mathrm{~g}$.

(Received for publication August 24, 1981.) 